\title{
Sobre la naturaleza y efectos de la producción, la distribución \\ y el consumo de la publicidad en la industria cultural
}

José Ramón Sánchez Guzmán

Universidad Complutense de Madrid

RESUMEN

El propósito de nuestro trabajo ha sido analizar la publicidad dentro del contexto de la cultura de masas dominante en las sociedades capitalistas avanzadas y su relación dialéctica con ella, al constituir la publicidad no sólo un espejo fiel de esa cultura, sino que, incluso, puede modificar las normas que le son habituales. Como, por otro lado, la generalización de la cultura de masas ha dado lugar al nacimiento de una industria capaz de elaborar los productos culturales estandarizados que necesita el consumo masivo de cultura, al entroncar la publicidad en ella pueden estudiarse la naturaleza y los efectos del proceso de producción, distribución y consumo del mensaje publicitario como producto cultural.

Palabras clave: Publicidad, Cultura de Masas, Medios de Comunicación de Masas. 


\section{INTRODUCCIÓN}

Desde que, hace más de cinco décadas, los teóricos de la Escuela de Frankfurt acuñaran el término «industria cultural», el fenómeno que lo define no ha perdido su vigencia y, lo que es más importante, ha adquirido carta de naturaleza global a partir del proceso de mundialización de lo que ha venido en denominarse «el modo de vida occidental». Dada, por otra parte, su relación con otro fenómeno como es el de la cultura de masas, ha de pensarse que el estadio en que los temas imaginarios sustentan esa cultura sufre las presiones de la industria y el comercio, presiones que están dirigidas a dar salida a los productos de consumo. Y, así, en ese estadio es en el que se opera una ósmosis multiforme entre publicidad y cultura de masas.

Téngase en cuenta, además, que el desarrollo y extensión de los mensajes publicitarios, dentro de la compleja gama de estímulos que hoy afectan la existencia cotidiana en las sociedades capitalistas avanzadas, implica una poderosa intervención en la conciencia de los individuos a todos los niveles: desde una determinación ideológica hasta la implantación de modelos de conducta, pasando por la configuración de una memoria colectiva y una conformación de la sensibilidad. Esto y otros efectos constituyen el punto central sobre el que gira el presente trabajo.

\section{LA PUBLICIDAD EN EL CONTEXTO DE LA INDUSTRIA CULTURAL}

Un análisis completo del concepto de industria cultural (ver, por todos, Horkheimer y Adorno, 1992) puede realizarse estudiando cada uno de los elementos que componen su designación, es decir, analizando los calificativos «industria»y «cultura».

El término «industria», en el contexto de nuestro estudio, ha de hacer referencia al proceso de estandarización del producto cultural a través de la división social del trabajo y gracias a la racionalización de las técnicas de distribución y consumo, técnicas que son parte integrante de las de producción, distribución y consumo de los bienes materiales. Se deduce de aquí que el producto del espíritu se convierte íntegramente en una mercancía. Esa conversión de la creación cultural en una mercancía suele denominarse «segunda industrialización» $y$, aun cuando es una característica singular del siglo xx, la conversión de un producto que cubre necesidades de la fantasía en una mercancía aparece en el sistema capitalista dentro de sus primeras etapas de la concurrencia. Así fue detectado por Marx (1968) cuando afirmó que la riqueza, en las sociedades donde impera el modo de producción capitalista, se anuncia como una inmensa acumulación de mercancías. La mercancía es primero un objeto exterior, una cosa que por sus propiedades satisface necesidades hu- 
manas de cualquier especie. Que dichas necesidades tengan por origen el estómago o la fantasía, señala Marx, su naturaleza no cambia nada el asunto.

La «cultura», también en el contexto de nuestro estudio, puede definirse como un conjunto de normas, símbolos, mitos e imágenes que son asumidos por el individuo y determinan sus sentimientos e instintos. Y, en este sentido, la cultura de masas es una verdadera cultura: está constituida por un cuerpo de símbolos, de mitos y de imágenes que configuran la vida práctica, real o imaginaria. Pero, paralelamente a disponer de los elementos constituyentes de toda cultura, posee algunos rasgos nuevos que la distinguen de todas las anteriores. En efecto, si bien las sociedades avanzadas son multiculturales (pues en ellas se desarrollan las culturas nacionales, la cultura religiosa y la cultura humanística), al integrarse la cultura de masas en el seno de las distintas culturas no puede ser totalmente autónoma, como tampoco la única existente. Pero sí puede decirse que constituye la corriente cultural hegemónica en las sociedades avanzadas y, principalmente, según Morin (1970), la primera cultura universal que ha existido en la Historia Universal.

Pues bien, ¿cuál es el papel que juega la publicidad en el contexto de la industria cultural? Nuestro análisis ha puesto de manifiesto, al examinar la literatura teórica y profesional al respecto, que la necesidad de que el mensaje publicitario se introduzca en la cultura en que están inmersos sus receptores a fin de que el mensaje sea efectivo es generalmente reconocida. $Y$, así, existe un consenso en afirmar que la primera necesidad que tiene el anuncio publicitario es ponerse a ritmo igual que la cultura, proponer al cliente unas satisfacciones simbólicas para sus tensiones que resulten conformes a los modelos socialmente valorizados y un modelo identificador, imagen de sí mismo, que se encuentra a tono con la cultura, bajo pena de ver cómo se alzan barreras. Hay quien llegó a decir (Dichter, 1963) que la actividad publicitaria es un problema de la antropología cultural y, en general, puede afirmarse que la cultura de masas sirve como base de sustentación a la publicidad y opera en el mismo sentido que ella, sin concretar los caminos que conducen a la felicidad prometida. De aquí la frase de McLuhan (1973) cuando señaló que la vida total de cualquier cultura tiende a ser propaganda.

Considerando con detalle los aspectos peculiares de la cultura de masas, puede concluirse que éstos responden a una simbiosis entre publicidad e industria cultural. En efecto, el nacimiento de una y otra se produce en una misma etapa cronológica no por pura casualidad, sino por la común raíz imaginativa-consciente que ambas conllevan. También la publicidad utiliza los mass media como canal material de su mensaje, además de desarrollar canales de comunicación propios como el cartel. Pero, principalmente, la publicidad se apoya en el contenido cultural imperante, utilizando sus símbolos, creencias y mitos. Los mitos del héroe, de la juventud, del amor, del erotismo, aparecen 
en la publicidad para provocar en el receptor un mecanismo identificativo-proyectivo que le conduzca hacia el consumo. $Y$ lo verdaderamente importante es comprender que mientras la publicidad induce hacia la posesión de un producto particularizado, la cultura de masas es la encargada de inducir hacia la posesión de productos en general, tanto reales como imaginarios.

Por lo que respecta al contenido cultural del mensaje publicitario existe una relación inversa entre publicidad y cultura de masas. En efecto, si bien la publicidad puede considerarse como un producto de la industria cultural, no lo es menos que el mensaje publicitario, además de ofrecer un objeto material, es portador de un mensaje cultural. Dicho de otra forma: el mensaje publicitario comunica un conglomerado de normas, símbolos, mitos e imágenes que es asumido por el individuo y determina sus sentimientos e instintos.

Finalmente, es preciso señalar otra importante relación entre publicidad y cultura de masas derivada de las conexiones económico-financieras que existen entre ellas. Los presupuestos publicitarios crean emisoras de radio y televisión, sostienen la prensa, ayudan económicamente a los locales cinematográficos. Las formas particulares de financiación de los medios de comunicación a través de la publicidad implicarían un estudio administrativo sobre las reglamentaciones legales al respecto en cada país, estudio que queda fuera del objeto de este trabajo.

\section{LA PRODUCCIÓN DEL MENSAJE PUBLICITARIO Y LA CULTURA DE MASAS}

La creación del mensaje publicitario puede asimilarse a un proceso de producción en el que, como tal, intervienen el factor trabajo, la materia prima y la técnica. El primero posee la característica de su alto nivel de cualificación profesional y suele nutrirse de especialistas en otras disciplinas (sociólogos, psicólogos, economistas, etc.). En la segunda, además de los productos estrictamente físicos (papel, tintas, película, etc.), ocupa un importante lugar el contexto cultural en el que se encuentran inmersos los consumidores y que es utilizado como «materia prima» del mensaje publicitario. La tercera ha ido evolucionando con el devenir histórico y desarrollando métodos propios, entre los cuales es necesario destacar, por su importancia, la investigación motivacional.

Pues bien, la cultura de masas se relaciona con la publicidad de dos formas directamente unidas entre sí: la cultura de masas es base de sustentación del mensaje publicitario al utilizar éste todo el mundo imaginario y simbólico de aquélla, pero, a la vez, el mensaje publicitario es portavoz de los mitos creados por la cultura de masas, no sólo utilizándolos, sino también reforzándolos, inclusos creando otros nuevos. Los mitos son elementos que se in- 
troducen en el proceso de producción del mensaje publicitario gracias a la relación dialéctica que se establece entre la cultura de masas y la publicidad.

Pero, aunque los héroes modernos mitificados por la publicidad (la estrella famosa, el jugador de fútbol y hasta miembros de la aristocracia) sean unos de los más utilizados por la publicidad, es el mito del erotismo el que supera a todos los demás por su generalización: no sólo tienen un fuerte contenido erótico los anuncios de prendas interiores femeninas, sino que también existe en los de automóviles, en los de electrodomésticos y en los de productos alimenticios.

Marcuse (1972) fue uno de los primeros pensadores que utilizó la relación entre el capitalismo avanzado y el erotismo publicitario, señalando que ése cumple un importante papel de «desublimación represiva», ya que la civilización industrial avanzada opera con un mayor grado de libertad sexual. En la relación entre publicidad y cultura de masas, por lo que se refiere al erotismo, Marcuse (como otros muchos autores) define aquélla como el elemento causal, ya que el gran desarrollo del erotismo en todas las esferas de la vida viene determinado por las exigencias de la industria publicitaria. Sin embargo, la erotización se encuentra limitada en publicidad al estar regida por el principio de la realidad (sometido a su vez a las leyes del mercado capitalista y, por tanto, del consumo) y no por el principio del placer.

Por otro lado, la limitación del erotismo en la producción del mensaje publicitario viene también determinada por criterios de eficacia, ya que si se diera a consumir, como tal, no cumpliría su función publicitaria. Esto implica que el erotismo sea cuidadosamente mantenido dentro de unos límites, a fin de evitar que el impacto del mensaje pase de la incitación publicitaria a consumir al consumo directo del erotismo del mensaje.

En efecto, como ejemplo, baste considerar que el hombre libidinoso que encuentra una gran satisfacción en ojear las páginas publicitarias de las revistas femeninas, dado que en ellas abundan los desnudos, no sabrá justificar tal lectura ante su esposa aconsejándola una determinada marca de sujetadores. Habrá, pues, percibido los desnudos pero no la publicidad. El erotismo proyectivo, pues, está en conflicto latente con el erotismo publicitario. De lo que se infiere que la publicidad puede valerse del erotismo, pero no puede utilizar la pornografía. Y, de esta forma, es la propia limitación erótica la que, entre otros aspectos, determina la eficacia a largo plazo del mensaje publicitario puesto que se suceden, en cadena, tres estados psíquicos del receptor del mensaje: una euforia (erotización limitada) al recibir el mensaje, un consuelo (semigratificación) al consumir el objeto anunciado y una servidumbre respecto al objeto que es rodeado de la cualidad mágicomitológica de un eros inalcanzable. Es por ello por lo que algunos autores (ver, por 
todos, Baudrillard, 1974) ven en la dialéctica frustración-gratificación el principio rector de la publicidad moderna.

Por lo que se refiere a la técnica utilizada, la evolución histórica de la publicidad también pone de manifiesto que en el proceso de creación del mensaje publicitario llegó a hacerse necesaria una nueva técnica de investigación que actuara en dos vertientes: primero, conocer las motivaciones para realizar un acto general y el de compra en particular (es decir, investigar al consumidor) y, segundo, tras conocer qué elementos crea la motivación hacia la compra, sugerir al consumidor «remedios» bajo la forma de gratificaciones producidas por la descarga simbólica de una energía acumulada. Todo ello se consigue mediante una serie de conocimientos científicos (sociología, psicología, semiología, etc.), aunque es la psicología, y en particular el psicoanálisis, quien ha planteado las bases científicas más importantes de la investigación motivacional.

La investigación motivacional aplicada al proceso de producción del mensaje publicitario puede dividirse en tres etapas. En la primera se elaboran unas técnicas de investigación del consumidor encaminadas a descubrir (segunda etapa) las motivaciones y frenos que le inducen o le retiran del acto de compra, introduciendo luego las conclusiones obtenidas (tercera etapa) en el proceso productivo del mensaje publicitario. Dado que tanto el estudio de las motivaciones como la aplicación de sus resultados a la creación publicitaria requieren referirse al caso concreto del producto y del consumidor, es únicamente en las técnicas de investigación donde se han dado reglas generales de análisis y de aplicación universalizada.

La segunda etapa (el estudio de las motivaciones) es el eje central de la obra de Dichter, en cierto modo el mayor impulsor de esta técnica (Dichter, 1963). Y ese estudio se propugna realizar a través de lo que este autor denomina «nuestro modo de pensar motivacional». Sin embargo, este modo de pensar sólo existe respecto a un contexto y un producto dados y, por ello, es imposible extraer reglas universalmente válidas y aplicables a todo estudio motivacional. En este sentido, se han llegado a delimitar (Joannis, 1969) seis zonas de investigación sobre el acto de compra concreto: el contexto psicológico en que se encuentra el producto, las motivaciones y frenos de compra, el significado del producto, la imagen de marca, el estudio del consumidor y la descripción del acto de compra.

\section{LA DISTRIBUCIÓN DE LA PUBLICIDAD: LOS MASS MEDIAY EL CARTEL}

Es sabido que la distribución de cualquier mensaje se realiza siempre mediante el canal que une al emisor del mismo con el receptor. En el caso de que este receptor sea de ca- 
rácter masivo, la comunicación exige necesariamente un medio de comunicación de masas. Y si el mensaje es de tipo publicitario, por razones de eficacia económica, utilizará fundamentalmente medios de comunicación masivos, tanto los creados por la industria cultural como los creados por la propia publicidad.

Entre los medios de comunicación creados por la industria cultural (prensa, radio, cine y televisión, fundamentalmente) y la publicidad se establecen relaciones muy diversas. Así, desde el punto de vista económico, la relación entre el mensaje cultural y el publicitario (dentro de los mass media como canal cultural) se refiere al problema de la financiación. La utilización masiva de los mass media culturales como canales de comunicación del mensaje publicitario ha supuesto una fuente de ingresos para aquéllos, hasta el punto que, en la actualidad, su subsistencia económica depende de esta fuente.

Sin embargo, existe un canal de uso exclusivo del mensaje publicitario, como es el cartel, sobre el que se centran las consideraciones generales acerca de los medios de distribución del mensaje publicitario que se exponen a continuación.

La función primordial del cartel es la persuasión. En sentido comercial, su razón económica es primordial, punto de vista que, sin embargo, no anula su aspecto cultural, difícil de evaluar por su contenido imaginario e inconsciente. Aunque la importancia de este aspecto (principalmente mitológico y artístico) queda reducida en su subordinación al económico.

Aparte de esta función primordial del cartel, se pueden señalar otras (Moles, 1990) divididas en dos niveles diferentes. Un primer nivel explícito reuniría las funciones de información, convicción y económica. Y otro se refiere a las funciones de tipo educativo, ambiental, estética y creadora.

La función de información se concreta al considerar el cartel como un canal entre el emisor y el receptor para dar a conocer la existencia de productos de consumo. La información se puede cargar más o menos en alguna de las dos partes del cartel (texto e imagen) según el carácter ambiguo de uno de ellos. Pero el cartel no se limita únicamente a describir el producto, sino que sugiere su consumo de una manera insinuante. Aparte de las técnicas generales de creación motivacional propias de la publicidad moderna, el cartel reúne unos factores específicos que conciernen a la imagen (composición, color, etc.).

La función económica se refiere al rendimiento del cartel, es decir, a su eficacia en cuanto creador de motivaciones hacia el acto de compra. Para ello, el creador del cartel debe tener en cuenta la psicosociología del consumidor: el impacto de lo novedoso es, si cabe, el elemento fundamental del comportamiento psicosociológico del receptor, en cuanto se refiere 
al cartel. La búsqueda incansable de nuevos medios de atraer la atención del receptor y de persistir en su memoria condiciona el rendimiento del cartel y, por lo tanto, su función económica.

El segundo nivel de funciones se refiere a toda una serie de mecanismos psicosociológicos que determina el cartel en el consumidor del mensaje y no derivados del carácter intrínseco del propio cartel, como las funciones anteriores. A las ya citadas, educadora, ambiental, estética y creadora, puede añadirse otra: la función aseguradora. Ésta se refiere a los mecanismos psicológicos del consumo publicitario moderno (la identificación y la proyección) que aparecen en el cartel con cualidades específicas determinadas por el fin comercial del mensaje.

La función educadora del cartel respecto al espectador es un efecto de las tesis macluhanianas de la comprensión de los medios como extensiones del hombre (McLuhan, 1968). El cartel, en tanto que es una estructura dotada de formas y colores, engendra, en el seno del receptor, nuevos hábitos perceptivos. Constituye una traducción original de la experiencia humana. Los signos gráficos e icónicos sustituyen, sin eliminarlos totalmente, a los signos tipográficos, creando de esa manera una nueva forma de inteligibilidad que desemboca directamente en el mundo exterior y obliga a una participación intensa del receptor. La demostración científica de la tesis macluhaniana, aplicada a los mensajes audiovisuales, remite a un problema puramente antropológico y es en este aspecto desde donde más ha sido atacado.

La función ambiental del cartel hace referencia a su consideración como elemento del paisaje urbano. Algunos autores ven en este elemento su carácter positivo en cuanto factor decorativo: la luz y el color de los carteles vendría a decorar el triste y gris escenario urbano de las ciudades industriales. Otros, sin embargo, ven los peligros que puede representar una política anárquica del cartelismo publicitario, además de que, desde el punto de vista técnico, una fuerte saturación del entorno visual mediante carteles puede reducir su eficacia al provocar un rechazo del receptor. Solamente un control planificado del cartelismo, en cuanto a color, tamaño y colocación, puede acrecentar su función decorativa (aunque es innecesario señalar la difícil realización práctica de tal pretensión, por razones de índole económica) y, en este sentido, son interesantes las aportaciones urbanísticas y arquitectónicas (Venturi y Brown, 1991) que señalan cómo no sólo es preciso tener en cuenta el entorno comercial de calles y autopistas para proyectar arquitectónicamente, sino que los elementos artísticos y decorativos de la publicidad cartelista deben integrarse en los edificios y en el espacio urbano. 


\section{LOS EFECTOS DEL CONSUMO MASIVO DE LA PUBLICIDAD}

Debe enunciarse, como premisa de partida, que no es lo mismo el consumo del mensaje publicitario que el consumo de mercancías, puesto que el primer fenómeno es un factor de motivación para que ocurra el segundo. Pero es indudable que la noción de consumidor corresponde a la misma realidad sociológica en un caso como en otro. El emisor del mensaje publicitario canaliza su comunicación hacia el grupo sociológico denominado consumidor por ser el que reúne las características y facultades que le capacitan para consumir mercancías producidas. El consumidor lo es en tanto que consume mercancías, pero, a la vez y por esta misma razón, es el receptor (consumidor) del mensaje publicitario, en cuanto que el mensaje, como todo mensaje cultural, es mercancía.

Para el estudio de los efectos que provoca el consumo de los mensajes publicitarios resulta de gran utilidad el conocido «análisis funcional» desarrollado por B. Malinowski, R. K. Merton y T. Parsons, entre otros. Como se sabe, en él se diferencia entre el «objetivo» de una actividad social determinada (propósito principal y explícito que pretende el sujeto que realiza la actividad) y la «función» (consecuencias secundarias y no deseables en primera instancia que acarrea dicha actividad). Dentro de las «funciones» se pueden diferenciar, a su vez, las «manifiestas», que serían las consecuencias previsibles, y las «latentes», que aparecen de forma imprevisible. Por último, existen las «disfunciones», definidas como consecuencias, ya sean manifiestas o latentes, de carácter negativo desde el punto de vista social.

Ahora bien, al referirse al mensaje publicitario la diferencia entre objetivos y funciones varía. En efecto, el productor del mensaje publicitario (emisor) realiza la actividad de la comunicación con el objetivo único de conseguir el incremento de ventas del producto anunciado y, por lo tanto, todos los efectos sociales e individuales que produce sólo pueden ser calificados como funciones según el análisis funcional. Es por ello por lo que se hace preciso realizar otra clasificación distinta de esas funciones, teniendo en cuenta que tanto los «objetivos» como las «funciones» de la cultura de masas aparecen en la publicidad operando de forma diferente y que existen otras específicas que se derivan de la propia actividad publicitaria. Se trataría, pues, de analizar las funciones culturales de la actividad publicitaria sin diferenciar las positivas de las negativas (disfunciones), puesto que ello supondría tomar una postura ideológica al respecto y sin diferenciar tampoco las manifiestas y las latentes, ya que ello sólo es posible realizarlo en casos concretos de actividad publicitaria.

Las funciones culturales de la publicidad se encuentran estrechamente relacionadas con su carácter de vinculación a la industria cultural en su conjunto. Baste resaltar cómo la pu- 
blicidad se convierte en una parte de la cultura de masas, porque cumple los dos principios básicos en que se asienta toda teoría de la cultura de masas: el universo imaginario que se introduce dentro del individuo mediante los mecanismos de identificación y proyección, y la transformación de todo mensaje cultural en un producto mercantil. Concretando en la función que cumple el mensaje publicitario al ser consumido como parte de la cultura de masas, se desprende que ambos apuntan hacia los mismos objetivos ideológicos, actuando como un refuerzo acumulativo y persistente sobre el individuo.

Merece destacarse que la publicidad también cumple el papel de ser un sustituto de la incomunicación. Ya hace tiempo se demostró (Riesman, 1971) que la publicidad, con el consiguiente acto de compra dirigido, provoca un mecanismo psicosocial que viene a sustituir la falta de comunicación existente en las sociedades industriales avanzadas. El efecto o función de comunicación que, evidentemente, aporta la publicidad mitiga la angustia de la soledad, es decir, una comunicación vertical y unidireccional sustituye a otra comunicación horizontal y bidireccional.

Finalmente, otra función de la publicidad se refiere a su carácter lúdico y espectacular. El elemento juego está presente en todas partes y a todos los niveles de la cultura de masas. Está presente, ante todo, bajo la forma más manifiesta y abierta, es decir, la de los juegos de televisión, los grandes concursos y los pequeños acertijos cotidianos de los periódicos. Está presente también, a un nivel más profundo, por la presentación lúdica de las informaciones en los medios de comunicación y el mensaje publicitario, como parte integrante de este mundo, y, además, fuertemente relacionado en muchos aspectos con él (en tanto que lo financia), participa del carácter lúdico de la cultura de masas, haciendo que los ciudadanos consuman el entorno imaginario y espectacular que rodea a las mercancías propuestas para la venta, despertando su interés, avivando su curiosidad y provocando su adhesión y posterior compra de los productos anunciados.

\section{REFERENCIAS}

BAUDRILLARD, J. (1984): La sociedad de consumo, sus mitos, sus estructuras, Plaza y Janés, Esplugas de Llobregat (Barcelona).

DICHTER, E. (1963): La estrategia del deseo, Huelmul, Buenos Aires.

HORKHEIMER, M., y ADORNO, Th. (1992): «La industria cultural», en Industria cultural y sociedad de masas, Monte Ávila Eds., 3. ${ }^{a}$ ed., Caracas.

JOANNIS, H. (1969): Del estudio de la motivación a la creación publicitaria y a la promoción de ventas, Paraninfo, Madrid.

MARCUSE, H. (1972): El hombre unidimensional, Seix Barral, Barcelona. 
MARX, C. (1968): El Capital, Fondo de Cultura Económica, México.

McLUHAN, M. (1968): Comprensión de los Medios, Diana, México.

McLUHAN, M., y WATSON, W. (1973): Del Cliché al arquetipo, Diana, México.

MULES, A. (1970): L’Affiche dans la société urbaine, Dunod, París.

MORIN, E. (1970): «De la culturanalyse à la politique culturelle», en Communications, n. ${ }^{14}$, Éditions du Seuil, París.

RIESMAN, D., et. al. (1971): La muchedumbre solitaria, Paidós, Buenos Aires.

VENTURI, R., y BROWN, S. (1991): Aprendiendo de todas las cosas, Tusquets, Barcelona.

The aim of our paper has been to analyse advertising within the context of popular culture that is dominant in advanced capitalist societies and its dialectical relationship with it, since advertising is not only a true mirror of such culture, but can also modify its most habitual standards. How, on the other hand, the generalization of popular culture has given rise to the birth of an industry capable of producing the standardized cultural products that massive culture consumption requires, as connecting advertising to it the nature and effects of the process of production, distribution and consumption of the advertising message as a cultural product can be studied.

Key words: Advertising, Popular Culture, Popular Communication Media. 